\title{
Growth hormone secretion, fatigue and quality of life after childhood traumatic brain injury
}

\author{
N Daskas', P Sharples ${ }^{2}$, M Likeman ${ }^{3}$, S Lightman ${ }^{4}$ and E C Crowne ${ }^{1}$ \\ ${ }^{1}$ Department of Paediatric Endocrinology, ${ }^{2}$ Department of Paediatric Neurology, University Hospitals Bristol, Bristol, \\ UK, ${ }^{3}$ School of Clinical Sciences, University of Bristol, Bristol, UK, and ${ }^{4}$ Department of Radiology, University Hospitals \\ Bristol, Bristol, UK
}

Correspondence should be addressed to E C Crowne

Email

Liz.Crowne@UHBristol.nhs.uk

\begin{abstract}
Context: Traumatic brain injury (TBI) is a recognised cause of hypopituitarism in adults but the prevalence after childhood TBI remains controversial.

Objective: To investigate long-term endocrine outcomes and quality of life (PedsQL and QoL-AGHDA (Quality of Life in Adult Growth Hormone Deficiency Assessment)) following childhood TBI.

Design: Prospective study.

Methods: Participants with moderate/severe TBI $(n=31)$ and controls $(n=17)$. Mean (range) age: $19.8 \pm 4.2(11-26)$, time post TBI: 9 (7-11) years. Detailed endocrine evaluation of stimulated (insulin tolerance test (ITT)) and spontaneous GH secretion (overnight profile) was undertaken in the TBI group; QoL and neuroimaging in both groups.

Results: No participant had seizures, short stature, precocious puberty or hypothyroidism. In 6/25 the ITT GH response was below age-defined cut-offs and cortisol $<500 \mathrm{nmol} / \mathrm{L}$ in 2/25. Mean spontaneous GH secretion was $<3.1 \mu \mathrm{g} / \mathrm{L}$ in 16/22 but peak GH was low only in 1/22 profiles. One patient had abnormal spontaneous and stimulated GH secretion and hypogonadism. Fatigue and depression scores were higher in TBI patients $(P=.011$ and $P=.020)$. Fatigue correlated with measures of spontaneous but not stimulated GH secretion. Overall QoL (PedsQL) did not differ between groups but specific attributes of health state (cognition, memory) were impaired in TBI patients. Pituitary neuroimaging was normal in all participants.

Conclusions: Fatigue and depression were common 8-10 years post childhood TBI. One individual had GHD (1/22) using rigorous diagnostic criteria. A single ITT potentially over-diagnosed GHD in 25\% (6/25) without clear correlation with symptoms underlying the importance of using two diagnostic tests in TBI survivors.
\end{abstract}

\section{Introduction}

Traumatic brain injury (TBI) is the leading cause of acquired neurological morbidity in UK children with annual hospital admission of 1/100-200 children (1). The Glasgow Coma Scale score (GCS) has been used to signify the severity of TBI (GCS of 13-15 signifies mild, 9-12 moderate and 8 or below severe TBI). TBI has been associated with permanent post-traumatic hypopituitarism (PTHP) (2) in adults. Reported prevalence ranges in the acute post-traumatic period from 5\% up to $80 \%$ (3). This variation reflects methodological differences in inclusion criteria, time since TBI (higher prevalence reported early following TBI), use of different diagnostic tests and cutoff values. Although multiple hormone deficiencies have been described, most TBI survivors have a single axis (4) deficiency, usually GH deficiency (GHD). There is however much less substantive evidence of PTHP

Published by Bioscientifica Ltd 
prevalence and clinical outcome after childhood TBI. In a study of 198 paediatric survivors of TBI with MRI changes, all participants had normal pituitary function using two stimulation tests (5) while in a more recent study, GHD was confirmed in 5/61 children with severe TBI who were retested 5 years post TBI (6). Conversely, other studies reported $10-40 \%$ incidence of hypopituitarism 1-3 years post TBI but without however using stringent diagnostic criteria $(7,8)$. Currently, there is no consensus for routine surveillance after childhood TBI. Even growth monitoring - a key indicator of childhood pituitary function - is not consistently undertaken post TBI (9).

KHINES (Kids' Head Injury Neuro-Endocrine Study) aimed to determine the long-term prevalence of neuroendocrine consequences following childhood TBI with detailed endocrine studies, including assessment of physiological and stimulated GH secretion.

\section{Subjects and methods}

\section{Ethical approval}

The study protocol was approved by the North Somerset and South Bristol Research Ethics Committee (Study No $\mathrm{CH} / 20090 / 3273)$. Informed consent/assent was obtained from participants or parent/legal guardian as appropriate for age and all assessments were completed within 6 months.

\section{Participants}

Inclusion criteria: all participants of the Kids' Head Injury Study (KHIS) - a prospective neuropsychology study of children, recruited immediately post TBI (2002-2004). Control participants in KHIS were non-injured school children matched for age, sex, socio-economic status and pre-TBI academic attainment. The original research team psychologist contacted KHIS participants asking if they would consider participating in KHINES. Recruitment was over 2 years (2011-2013). Age (range) at assessment was 19.8 (11.3-26.6) years and time since TBI was 9.0 (6.8-10.8) years. There were no differences between participating and non-participating TBI individuals with regards to age, gender, time since TBI, duration of post-traumatic amnesia, days in intensive care and type of structural abnormalities on acute neuroimaging (extradural/subdural haemorrhage, diffuse axonal injury or skull fracture).

Exclusion criteria included pregnancy, history of significant pre-TBI endocrine dysfunction, psychological or non-TBI medical problems and drugs (steroids) affecting interpretation of results and repeat TBI (any severity).

\section{Clinical and auxological assessment}

Detailed data concerning the severity and mechanism of TBI and outcomes were available from the KHIS database. All participants were examined by the same researcher and were asked to complete questionnaires to assess quality of Life (QoL), fatigue and had neuroimaging unless contraindicated. In addition, TBI participants underwent detailed endocrine investigations.

\section{Questionnaire measures}

The Paediatric Quality of Life Inventory (PedsQL 4.0) has been applied to children with paediatric TBI and has detected cognitive differences among groups of children with varying severities of TBI (10). The Fatigue Scale (Chalder et al. (11)) is a self-reported measure of tiredness. It produces a total score, with subscores reflecting mental fatigue (four items) and physical fatigue (seven items). The Beck Depression Inventory (BDI-II) (12) is a 21-item selfreport instrument for measuring the degree of depression in adults and adolescents. The Quality of Life Assessment of Growth Hormone Deficiency in Adults (QoL-AGHDA) is a disease-specific (i.e. GHD), patient needs-based HRQL instrument developed specifically to detect deficits in areas that are affected in adults with GHD. A score of 11 or more is suggestive of perceived impairment of quality of life (13).

\section{Neuroimaging}

Unless contraindicated, study participants were examined on a 3 T MRI scanner (Magnetom Skyra, Siemens Medical Systems). Sagittal and coronal T2 TSE (TR/TE 4430/89 ms; thickness $2 \mathrm{~mm}$; FOV 190; resolution $0.5 \times 0.5 \mathrm{~mm}$ ) and T1-weighted images (TR/TE 500/2.93; thickness $2 \mathrm{~mm}$; FOV 190) were obtained and were reported by the same expert consultant neuroradiologist blinded to clinical details. Pituitary volume was calculated using the ellipsoid formula.

\section{Endocrine investigations}

Ethics approval for blood tests was obtained only in TBI participants. Baseline investigations included free-T4, $\mathrm{TSH}$, testosterone (males), oestradiol (females), LH, FSH, prolactin (PRL), IGF-1, IGF-BP3 and plasma osmolality. 
GH status was assessed by 12-h overnight GH profile (20:00 h to 8:00h) and sampling every $15 \mathrm{~min}$ followed by an insulin tolerance test (ITT) the following morning. Blood sampling commenced $1 \mathrm{~h}$ after catheter insertion, participants were ambulatory, had an evening meal but only water from midnight. Participants slept and woke at their usual time. Blood samples were kept overnight at $5^{\circ} \mathrm{C}$ then centrifuged and stored at $-70^{\circ} \mathrm{C}$ until assayed within 3 months. GH profiles were compared with published data of 43 healthy participants (age: $16.1 \pm 1.1$ years) using the same GH assay with 30-min sampling. Mean spontaneous, nocturnal GH secretion in this group was $6.7 \pm 2.9(3.1-15.6 \mu \mathrm{g} / \mathrm{L})(14)$.

For the ITT, soluble insulin $(0.15 \mathrm{U} / \mathrm{kg})$ was given i.v. to induce hypoglycaemia (glucose $<2.2 \mathrm{mmol} / \mathrm{L}$ ). GH and cortisol were assayed at $-15,0,30,60,90$ and $120 \mathrm{~min}$. Diagnostic criteria used for GHD: young adult $<3 \mu \mathrm{g} / \mathrm{L}$, transition age $<5 \mu \mathrm{g} / \mathrm{L}$ and paediatric $<6.7 \mu \mathrm{g} / \mathrm{L}$ (15) and cortisol $500 \mathrm{nmol} / \mathrm{L}$.

\section{Assays}

GH and cortisol were assayed in duplicate using a commercial electrochemiluminescence immunoassay ('hGH' and 'cortisol'; Roche Diagnostics GmbH). Intraand inter-assay coefficients of variation (CVs) were GH 1.9 and $3.0 \%$ at $\mathrm{GH}$ concentrations of $0.163 \mu \mathrm{g} / \mathrm{L}$ and $8.23 \mu \mathrm{g} / \mathrm{L}$ and limit of detection $0.03 \mu \mathrm{g} / \mathrm{L}$; cortisol 1.5 and $1.7 \%$ at concentrations of $352 \mathrm{nmol} / \mathrm{L}$ and $717 \mathrm{nmol} / \mathrm{L}$ and limit of detection $0.5 \mathrm{nmol} / \mathrm{L}$. Serum IGF-1 and IGF-BP3 were assayed by Immulite 1000. Intra-assay and inter-assay CVs were IGF-I under 4 and $8 \%$ respectively for concentrations between 6 and $120 \mathrm{nmol} / \mathrm{L}$; IGF-BP3 5.6 and 9.9\%; 3.5 and $7.5 \%$ at concentrations of 1.6 and $6.8 \mathrm{mg} / \mathrm{L}$ respectively.

FT4, TSH, LH, FSH and PRL blood levels were measured by ECLIA, using a Modular E170 (Roche Diagnostics) with maximal inter-assay $\mathrm{CV}$ of 5.0\%.

\section{GH profile analysis}

Analysis of GH secretion was done using deconvolution. Deconvolution is the method by which the combined result of interlinked processes (i.e. secretion, distribution and elimination) is untangled to reveal the underlying components. The AutoDecon deconvolution algorithm (16) that was used in this study uses the assay as a scale factor and automatically inserts presumptive peaks after testing them for significance. The following initialisation settings were set: basal secretion: zero; concentration at time zero: zero; elimination half-life: 10-20minutes; standard deviation of the secretion events: one-half of the data sampling interval and zero secretion events. Peak spontaneous GH below the diagnostic ITT cut-off (17) or average overnight GH secretion below $3.1 \mu \mathrm{g} / \mathrm{L}$ were used as diagnostic criteria $(3.1 \mu \mathrm{g} / \mathrm{L}$ was the lowest mean GH level reported in 43 healthy subjects of similar age using the same GH assay as in KHINES (14)).

Approximate entropy (ApEn) was used to assess the serial orderliness (regularity) of GH secretion. ApEn is a number between 0 and 1 with larger values corresponding to greater randomness (18). The parameters used in this analysis ( $m=1$ and $r=20 \%$ ) are reproducible in endocrine practice (19).

\section{Statistical analysis}

Data are expressed as mean \pm standard deviation (mean \pm S.D.) or median (median (range)) if not normally distributed. Auxological measurements were converted to standard deviation scores (SDS) for comparisons (20). Parametric ( $t$-test) and non-parametric tests used were (Mann-Whitney $U$ and Wilcoxon signed-ranks for paired data). Associations and agreement between variables were explored using Pearson's correlation coefficient and Kappa respectively.

\section{Results}

\section{Participants}

Forty-eight out of 117 (31/61 mod/sev TBI and 17/56 healthy controls) agreed to participate in KHINES. TBI and control groups were similar with regard to height SDS (0.23 ( -2.0 to 2.8 ) vs 0.43 ( -1.1 to 2.8 ), $P=.462$ ), weight SDS (0.49 ( -2.6 to 3.8$)$ vs 0.79 ( -0.4 to -3.9$), P=.238)$ and BMI SDS (0.45 ( -1.8 to 3.2$)$ vs 0.64 ( -0.65 to 3.45 ), $P=.330)$. None of the participants had short stature compared with UK population standards.

\section{Baseline endocrine function}

All participants had normal thyroid and posterior pituitary function. Post-pubertal males had testosterone levels within the normal range.

Of the 11 female participants, seven were postpubertal, three pubertal (Tanner stage 3-4) and one was prepubertal (11.3 years old). Five were taking oral contraception. One post-pubertal female with secondary amenorrhea following TBI had low levels of oestradiol 
Table 1 TBI participants with abnormal GH response to ITT.

\begin{tabular}{|c|c|c|c|c|c|c|c|c|c|c|c|c|c|}
\hline & \multirow{2}{*}{$\begin{array}{c}\begin{array}{c}\text { Gender } \\
\text { (male, female) }\end{array} \\
\end{array}$} & \multirow{2}{*}{$\begin{array}{c}\text { Age } \\
\text { (year) }\end{array}$} & \multirow{2}{*}{$\begin{array}{c}\text { Time from } \\
\text { TBI (year) }\end{array}$} & \multirow[b]{2}{*}{ Height SDS } & \multirow[b]{2}{*}{ BMI SDS } & \multirow{2}{*}{$\begin{array}{l}\text { Injury } \\
\text { type }\end{array}$} & \multirow{2}{*}{$\begin{array}{l}\text { Injury } \\
\text { mechanism }\end{array}$} & \multirow{2}{*}{$\begin{array}{c}\text { ITT GH peak } \\
(\mu \mathrm{g} / \mathrm{L})\end{array}$} & \multirow{2}{*}{$\begin{array}{c}\text { IGF-1 } \\
\text { SDS }\end{array}$} & \multirow{2}{*}{$\begin{array}{l}\text { IGF-1 BP3 } \\
\text { SDS }\end{array}$} & \multirow{2}{*}{$\begin{array}{l}\text { ITT cortisol } \\
\text { peak (nmol/L) }\end{array}$} & \multicolumn{2}{|c|}{$\begin{array}{c}\text { Spontaneous GH } \\
\text { secretion }(\mu g / L)\end{array}$} \\
\hline & & & & & & & & & & & & Mean & Peak \\
\hline 1 & $\mathrm{~F}$ & 12 & 9.3 & 1.42 & 2.58 & Mod & Fall & 4.4 & 0.21 & 1.13 & 605 & - & - \\
\hline 2 & $\mathrm{M}$ & 22 & 10.1 & 1.10 & 1.30 & Mod & $\begin{array}{l}\text { Hit by } \\
\text { vehicle }\end{array}$ & 1.8 & -0.49 & -0.86 & 586 & 1.3 & 10.0 \\
\hline 3 & $\mathrm{~F}$ & 16 & 9.4 & 0.76 & 0.16 & Mod & $\begin{array}{l}\text { Hit by } \\
\text { vehicle }\end{array}$ & 3.7 & -2.39 & -2.14 & 584 & 1.3 & 2.7 \\
\hline 4 & $M$ & 24 & 8.6 & 0.23 & -1.04 & Sev & Fall & 0.1 & -0.46 & -0.74 & 501 & 0.5 & 9.9 \\
\hline 5 & M & 25 & 8.8 & -0.33 & 0.59 & Mod & $\begin{array}{l}\text { Hit by } \\
\text { vehicle }\end{array}$ & 0.1 & -0.30 & -0.51 & 526 & 1.7 & 9.4 \\
\hline 6 & $\mathrm{M}$ & 14 & 7.6 & 0.35 & -0.36 & Mod & Cyclist & 1.2 & -1.06 & -1.17 & 483 & 1.2 & 14.8 \\
\hline
\end{tabular}

( $<50 \mathrm{pmol} / \mathrm{L})$, gonadotropins, IGF-1 and IGFBP3 (-2.4 and -2.1 SDS respectively). All male participants were pubertal ( $n=9$, Tanner stage 4$)$ or post-pubertal $(n=11$, Tanner stage 5).

\section{Stimulated growth hormone and cortisol secretion}

Twenty-five of 31 TBI participants had a stimulation test (ITT). In 6/25 (4 male) the GH response to ITT was suboptimal using age-appropriate cutoff values (Table 1 ). In one male participant, the cortisol peak was also suboptimal $(483 \mathrm{nmol} / \mathrm{L})$. One female participant with amenorrhea and low gonadotropin levels (see above), demonstrated normal cortisol $(584 \mathrm{nmol} / \mathrm{L})$ but abnormal stimulated GH response (peak GH $3.7 \mu \mathrm{g} / \mathrm{L}$ ). Another female participant with suboptimal cortisol response $(392 \mathrm{nmol} / \mathrm{L}$ ) had normal GH response to ITT (peak GH $6.7 \mu \mathrm{g} / \mathrm{L})$.

IGF-1 SDS was not different between participants with normal and abnormal stimulated GH response $(-.48 \pm 1.1$ vs $-.74 \pm .82, P=.86)$ and peak stimulated GH response did not correlate with IGF-1 $(\rho=.21, P=.35)$, IGF-1-BP3 $(\rho=-.04, P=.87)$, IGF-1 SDS $(\rho=.07, P=.77)$ or IGF-1-BP3 SDS $(\rho=-.06, P=.79)$.

\section{Spontaneous growth hormone profiles}

Data from 22 overnight GH profiles (eight participants were not able to stay overnight but three had an ITT and one profile was incomplete) are shown in Fig. 1 and Table 2. All 22 participants who had an overnight profile also had an ITT.

As expected there is a difference between male and female profiles, with increased basal GH secretion in females and increased ApEn indicating higher temporal irregularity in overnight GH secretion. There was a trend to lower peak GH in females but this did not reach statistical significance. Overall, mean GH secretion was significantly lower compared to that reported in healthy individuals $(2.2 \pm 1.3$ vs $6.1 \pm 2.6 \mu \mathrm{g} / \mathrm{L}, P<.0001) \quad(14)$. Mean GH was under $3.1 \mu \mathrm{g} / \mathrm{L}$ in 16/22, 4 of whom had an abnormal response to ITT (indicating poor agreement between tests when using the above criteria (Kappa .096, $P=.49)$ ). Three of these four participants had peak overnight GH above the age-related cutoff and IGF-1 SDS above -0.5 . The fourth participant had low peak overnight GH of $2.7 \mu \mathrm{g} / \mathrm{L}$ and low IGF-1 SDS of -2.4 . Although four had an abnormal GH response to ITT (with low mean overnight secretion), 12 demonstrated a normal response. Neurosecretory dysfunction (normal stimulated but suboptimal spontaneous GH responses) has been described (21), although its clinical significance is not clear.

Pulsatility was preserved in all but one participant (female with amenorrhea and GHD) as at least four secretory events were detected with deconvolution analysis in all other profiles (including ones where the GH concentration curve would suggest a smaller number of secretory events as shown in Fig. 1).

In contrast to ITT results, measures of spontaneous GH secretion (average, maximum, mean secretion pulse mass) correlated with IGF-1 levels $(r=.74, r=.52, r=.75$, all $P<.05$ ). IGF-1 levels were also lower in the subgroup of TBI patients with mean, overnight GH secretion under $3.1 \mu \mathrm{g} / \mathrm{L}(33.4 \pm 7.1$ vs $45.7 \pm 7.1 \mathrm{nmol} / \mathrm{L}, P=.003,95 \%$ CI of difference 4.62-19.87).

There was no strong correlation between peak stimulated and peak spontaneous GH levels $(\rho=.17$, $P=.45$ ).

In descending order and using different diagnostic criteria and their combinations to estimate the frequency of insufficient GH secretion, 16/22 (72\%) had low mean overnight GH secretion, 6/25 (24\%) had abnormal ITT and $4 / 22$ (18\%) failed both. In only one overnight profile 

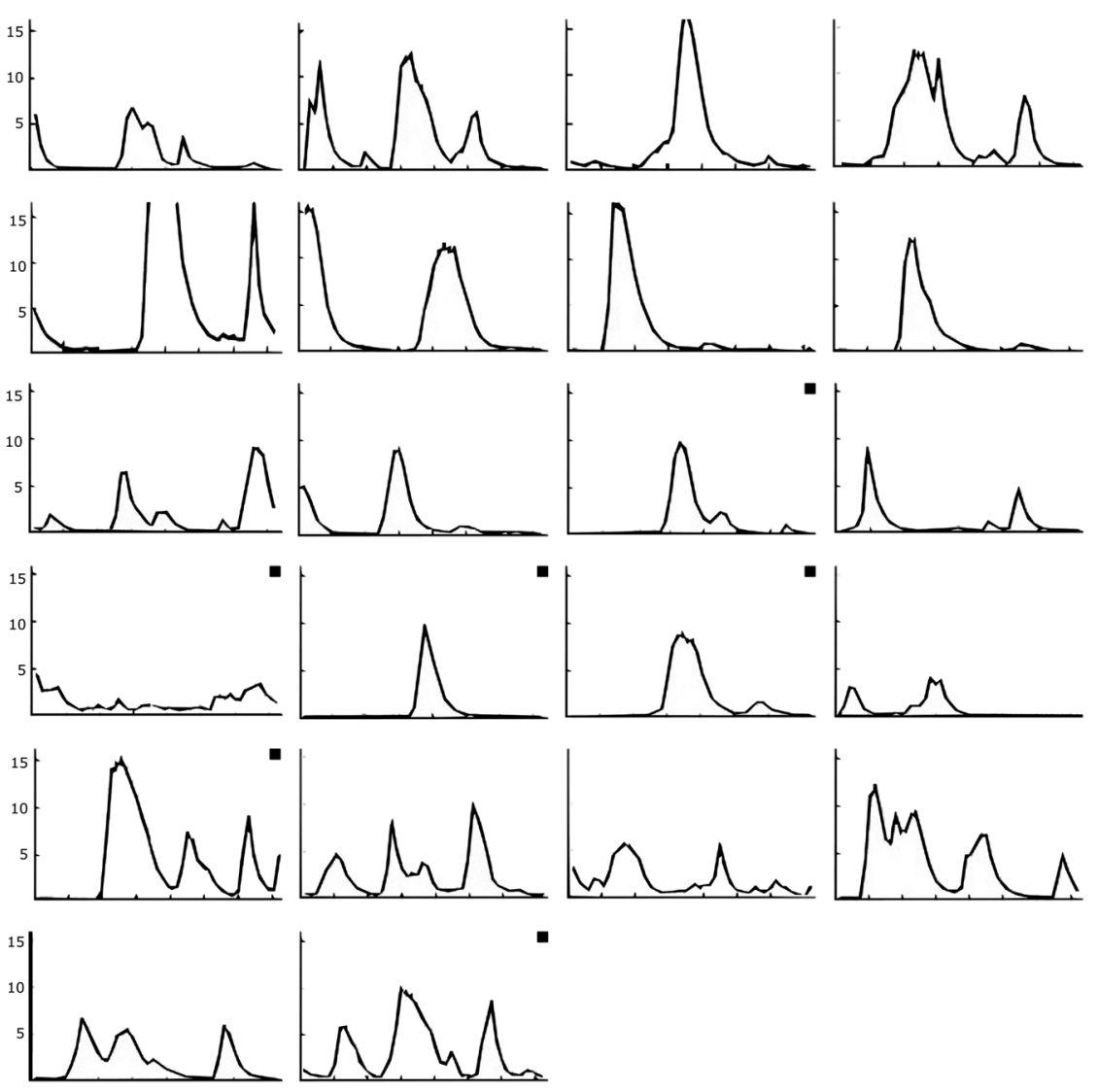

was the peak GH abnormal (1/22, 5\%). Mean overnight and stimulated $\mathrm{GH}$ secretion were also abnormal in the same profile.

\section{Quality of life}

Only TBI participants (9/30), but no controls had a Total PedsQL score of less than $69.7 \%$ which is the level for detecting QoL problems in children with chronic health conditions. QoL-AGHDA scores in adult TBI patients (14/20 responded) indicated poor QoL $(10.7 \pm 6.9,8 / 14$ had a score $>11$ ) and were higher when compared to

age and gender-weighted, general population UK data (difference 4.86, 95\% CI 1.3-8.3, $P<.01$ ). To further examine potential bias because of non-responders, the analysis was repeated using mean AGHDA scores from the general population (5.8 for males, 6.6 for females) for non-responders (22). QoL-AGHDA scores were again higher in the adult TBI group but the difference was smaller (difference 2.68, 95\% CI -.22 to $5.58, P=.068$ ). However, this cannot entirely rule out bias if, for example, some non-responders had scores better than average.

QoL-AGHDA scores correlated with fatigue scores $(r=.62, P=.002)$ but not with measures of $\mathrm{GH}$ secretion.

Table 2 Findings from deconvolution analysis of overnight GH secretion profiles in patients with moderate/severe TBI in childhood.

\begin{tabular}{l}
\hline \\
\hline Peak 12-h GH $(\mu \mathrm{g} / \mathrm{L})$ \\
Basal 12-h GH $(\mu \mathrm{g} / \mathrm{L})$ \\
GH half-life $(\mathrm{min})$ \\
Mean 12-h GH $(\mu \mathrm{g} / \mathrm{L})$ \\
GH secretory peaks over $12 \mathrm{~h}$ \\
Mean GH secretory pulse height $(\mathrm{mg} / \mathrm{L} / \mathrm{min})$ \\
Mean $\mathrm{GH}$ secretion pulse mass $(\mathrm{mg} / \mathrm{L})$ \\
ApEn $(\mathrm{GH})$
\end{tabular}

\begin{tabular}{c}
\hline Males $(n=15)$ \\
\hline $13.03 \pm 7.6$ \\
$0.0034 \pm .003$ \\
$22.6 \pm 5.5$ \\
$2.43 \pm 1.4$ \\
$7.3 \pm 2.6$ \\
$0.36 \pm .22$ \\
$7.9 \pm 6.02$ \\
$0.44 \pm .22$ \\
\hline
\end{tabular}

\begin{tabular}{c}
\hline Females $(n=7)$ \\
\hline $7.16 \pm 3.2$ \\
$0.011 \pm .008$ \\
$16.3 \pm 3.9$ \\
$1.78 \pm .9$ \\
$7.6 \pm 1.5$ \\
$0.39 \pm .34$ \\
$6.3 \pm 4.72$ \\
$0.65 \pm .17$ \\
\hline
\end{tabular}

\begin{tabular}{l}
\hline P value \\
\hline 0.066 \\
0.054 \\
0.015 \\
0.294 \\
0.831 \\
0.791 \\
0.532 \\
0.040 \\
\hline
\end{tabular}

\begin{tabular}{ccc}
\hline \multicolumn{2}{c}{$\mathbf{9 5 \%} \mathbf{~ C l}$ of difference } \\
\hline Lower & & Upper \\
\cline { 1 - 1 }-12.1882 & & 0.4358 \\
-0.00001 & & 0.015 \\
-11.163 & & -1.347 \\
-1.948 & & 0.6221 \\
-2.052 & & 2.528 \\
-0.022 & & 0.285 \\
-7.053 & & 3.755 \\
0.0106 & & 0.4086 \\
\hline
\end{tabular}




\section{Fatigue}

Fatigue scores were higher in TBI $(3.2 \pm 3.3)$ vs control group (.43 \pm .85$)$ using bimodal scoring (scale 0-11) $(P<.001)$. Bimodal scores of $\geq 3$ (239) or $\geq 16$ (Likert) are recommended for identifying significant fatigue; 13/28 TBI participants fulfilled these criteria compared with $1 / 14$ in the control group $(P=.011)$. Fatigue scores correlated negatively with PedsQL scores $(\rho=-.68$, $P<.001)$; participants with higher levels of fatigue having poorer QoL $(P<.001)$. Although fatigue was not associated with measures of stimulated GH secretion or IGF-1/ IGFBP3, mean secretion pulse height in overnight profiles was significantly lower in male participants with fatigue $(P=.022)$.

In four TBI participants (two males), the bimodal fatigue score was above 9 which is seen in Chronic Fatigue Syndrome (CFS) patients (23). Two of them completed all endocrine investigations. Both had normal stimulated GH response to ITT (6.2 and $14.3 \mu \mathrm{g} / \mathrm{L})$ but their mean overnight secretion was 1.2 and $1.8 \mu \mathrm{g} / \mathrm{L}$ with peak overnight GH levels of 4.1 and $8.6 \mu \mathrm{g} / \mathrm{L}$ respectively.

\section{Neuroimaging}

35/48 participants (14 controls, $21 \mathrm{TBI}$ ) had a head MRI scan (ten TBI were excluded due to metallic implants and three controls due to the possibility of metal fragments in their eyes).

In TBI participants 15/35 scans were abnormal. Reported abnormalities included contusions in 11, white matter shearing injury in 1 , frontal lobe cavities in 1 , reduced brain volume in 1 and acoustic neuroma in 1 (incidental finding). Pituitary morphology (both anterior and posterior) was normal in all participants and pituitary size did not differ between groups (TBI vs control, $1727 \pm 585$ vs $1480 \pm 493 \mathrm{~mm}^{3}, P=.884$ ). Pituitary volume did not correlate with measures of spontaneous or stimulated GH secretion.

\section{Discussion}

KHINES demonstrated persisting abnormalities in the GH/ IGF-1 axis in TBI survivors including multiple pituitary hormone deficiency in one participant. It also highlights the inherent difficulties in assessing GH status using both stimulated and/or spontaneous GH secretion in a dynamic hormone system. Measurement of peak level of spontaneous GH secretion (or number of peaks above a predefined cutoff) has been reported to provide higher diagnostic accuracy than the stimulated response (24) but the definition of a significant GH spontaneous peak remains controversial. Although studies in prepubertal children or adults have used a fixed GH level to define a normal response $(17,25)$, in KHINES we used strict criteria of a single peak above the standard age-related cutoff (same level used in ITT).

In a similar study by Wamstad et al. (25) that enrolled children and adolescents (age range 8-21 years) 3-4 years post TBI, the prevalence of GHD was $17 \%$ based on overnight GH secretion and $27 \%$ based on the stimulation test. Stimulation test results are comparable (KHINES $24 \%(6 / 25))$ but overnight GH secretion in KHINES was abnormal in $5 \%(1 / 22)$ using the age-related cutoff to classify abnormal GH profiles. Results are comparable if the same not age-related cutoff of $5 \mu \mathrm{g} / \mathrm{L}$ is used $(3 / 22$ $(14 \%))$.

Although abnormalities in the GH axis have been identified, anthropometric and physical function scores in our study group of TBI survivors were not different to the control group. Adult height was not a concern to any participant. However, QoL was reduced and high rates of fatigue and depression were observed in TBI survivors. There was no association between QoL, depression scores or fatigue and GH status as assessed using the ITT. This is in agreement with a previous report (26). There was however an association with spontaneous GH secretion as peak secretion amplitude was reduced in TBI males with fatigue. A similar pattern of GH secretion with reduced GH pulse amplitude but normal secretory event frequency and stimulated GH secretion has been described in patients with fibromyalgia. These patients demonstrate normal pituitary responsiveness to GHRH supporting the hypothesis of dysregulation at the hypothalamic or higher level (27). KHINES participants showed a similar pattern which has previously been described as neurosecretory dysfunction (normal stimulated but suboptimal spontaneous GH response) (21).

These interesting but subtle associations do not necessarily demonstrate causality and could be associated phenomena. However, if present, it would be reasonable to anticipate that untreated PTHP could impede recovery and rehabilitation of TBI survivors and contribute to the long-standing problems with fatigue, poorer HRQL and cognitive impairment.

The question remains as to what is the best way to assess GH axis integrity in children post TBI considering the low a priori likelihood of hypopituitarism as demonstrated in KHINES. We propose a pragmatic approach utilising two 
GH stimulation tests for TBI patients with low IGF-1 (or IGF-1 SDS <-2) and/or biochemical or clinical evidence of pituitary hormone deficiency. Current UK guidelines indicate a single dynamic test for patients with a known underlying cause for GHD but in light of our findings, we propose that TBI patients with significant fatigue or other symptoms affecting QoL but normal baseline endocrinology do need two abnormal stimulation tests (or combination of stimulation test and overnight profile if feasible) to diagnose GHD. It is also important to ensure that stimulation tests that involve administration of GHRH are avoided as these will underdiagnose GHD secondary to hypothalamic dysfunction.

The main limitation of KHINES was not having a control group for the endocrine investigation arm involving blood tests. Recruitment, however, was high and there was little variability with regards to time from injury (all between 7 and 11 years). KHINES is also one of the few paediatric TBI studies that used two endocrine tests to assess GH status and the first one to our knowledge that has used a combination of ITT and overnight profiles 10 years post TBI with analysis of GH pulsatility.

\section{Conclusion}

KHINES has demonstrated that the identification of PTHP after childhood TBI is challenging, but if stringent diagnostic criteria are used, long-term prevalence of PTHP in survivors of childhood TBI is less frequent than has been reported previously. Clinical criteria suggesting pituitary dysfunction obviously need investigation but with two GH stimulation tests especially in the context of low IGF-1 or biochemical evidence of other pituitary hormone deficiency.

Fatigue and depression are still prevalent 8-10 years post childhood TBI. Fatigue correlated with measures of spontaneous but not stimulated GH which may suggest dysfunction at the hypothalamic or higher rather than pituitary level. Any role for intervention with GH treatment requires further study in this cohort of patients who do not present with a typical GHD phenotype.

\section{Declaration of interest}

The authors declare that there is no conflict of interest that could be perceived as prejudicing the impartiality of this study.

\section{Funding}

Merck-Serono Inc. (unrestricted educational grant) and 'Above \& Beyond' (charitable funds).

\section{Acknowledgement}

CRIC Bristol (Clinical Research and Imaging Centre http://www.bristol. ac.uk/cricbristol/).

\section{References}

1 Kraus JF, Rock A \& Hemyari P. Brain injuries among infants, children, adolescents, and young adults. American Journal of Diseases of Children 1990144 684-691. (https://doi.org/10.1001/ archpedi.1990.02150300082022)

2 Agha A \& Thompson CJ. Anterior pituitary dysfunction following traumatic brain injury (TBI). Clinical Endocrinology 200664 481-488. (https://doi.org/10.1111/j.1365-2265.2006.02517.x)

3 Tanriverdi F, De Bellis A, Ulutabanca H, Bizzarro A, Sinisi AA, Bellastella G, Amoresano Paglionico V, Dalla Mora L, Selcuklu A, Unluhizarci K et al. A five year prospective investigation of anterior pituitary function after traumatic brain injury: is hypopituitarism long-term after head trauma associated with autoimmunity? Journal of Neurotrauma 201330 1426-1433. (https://doi.org/10.1089/ neu.2012.2752)

4 Schneider HJ, Corneli G, Kreitschman-Andermahr I, Rovere S, Bellone S, Bona G, Ghigo E \& Aimaretti G. Traumatic brain injury and hypopituitarism in children and adolescents: is the problem under-estimated? Pediatric Endocrinology Reviews 20074 205-209.

5 Heather NL, Jefferies C, Hofman PL, Derraik JG, Brennan C, Kelly P, Hamill JK, Jones RG, Rowe DL \& Cutfield WS. Permanent hypopituitarism is rare after structural traumatic brain injury in early childhood. Journal of Clinical Endocrinology and Metabolism 201297 599-604. (https://doi.org/10.1210/jc.2011-2284)

6 Dassa Y, Crosnier H, Chevignard M, Viaud M, Personnier C, Flechtner I, Meyer P, Puget S, Boddaert N, Breton S et al. Pituitary deficiency and precocious puberty after childhood severe traumatic brain injury: a long-term follow-up prospective study. European Journal of Endocrinology 2019180 281-290. (https://doi.org/10.1530/ EJE-19-0034)

7 Kaulfers AM, Backeljauw PF, Reifschneider K, Blum S, Michaud L, Weiss M \& Rose SR. Endocrine dysfunction following traumatic brain injury in children. Journal of Pediatrics 2010157 894-899. (https:// doi.org/10.1016/j.jpeds.2010.07.004)

8 Niederland T, Makovi H, Gal V, Andreka B, Abraham CS \& Kovacs J. Abnormalities of pituitary function after traumatic brain injury in children. Journal of Neurotrauma 200724 119-127. (https://doi. org/10.1089/neu.2005.369ER)

9 Moon RJ, Wilson P, Kirkham FJ \& Davies JH. Growth monitoring following traumatic brain injury. Archives of Disease in Childhood 200994 699-701. (https://doi.org/10.1136/adc.2008.145235)

10 McCarthy ML, MacKenzie EJ, Durbin DR, Aitken ME, Jaffe KM, Paidas CN, Slomine BS, Dorsch AM, Berk RA, Christensen JR et al. The Pediatric Quality of Life Inventory: an evaluation of its reliability and validity for children with traumatic brain injury. Archives of Physical Medicine and Rehabilitation 200586 1901-1909. (https://doi. org/10.1016/j.apmr.2005.03.026)

11 Chalder T, Berelowitz G, Pawlikowska T, Watts L, Wessely S, Wright D \& Wallace EP. Development of a fatigue scale. Journal of Psychosomatic Research 199337 147-153. (https://doi.org/10.1016/00223999(93)90081-P)

12 Gatewood-Colwell G, Kaczmarek M \& Ames MH. Reliability and validity of the Beck Depression Inventory for a white and MexicanAmerican gerontic population. Psychological Reports 198965 1163-1166. (https://doi.org/10.2466/pr0.1989.65.3f.1163)

13 McKenna SP, Doward LC, Alonso J, Kohlmann T, Niero M, Prieto L \& Wiren L. The QoL-AGHDA: an instrument for the assessment of quality of life in adults with growth hormone deficiency. Quality of Life Research 19998 373-383. (https://doi. org/10.1023/A:1008987922774) 
14 Radetti G, di Iorgi N, Paganini C, Gastaldi R, Napoli F, Lorini R $\&$ Maghnie M. The advantage of measuring spontaneous growth hormone (GH) secretion compared with the insulin tolerance test in the diagnosis of GH deficiency in young adults. Clinical Endocrinology 200767 78-84. (https://doi.org/10.1111/j.13652265.2007.02842.x)

15 Clayton PE, Cuneo RC, Juul A, Monson JP, Shalet SM, Tauber M \& European Society of Paediatric Endocrinology. Consensus statement on the management of the GH-treated adolescent in the transition to adult care. European Journal of Endocrinology 2005152 165-170. (https://doi.org/10.1530/eje.1.01829)

16 Johnson ML, Pipes L, Veldhuis PP, Farhy LS, Boyd DG \& Evans WS. AutoDecon, a deconvolution algorithm for identification and characterization of luteinizing hormone secretory bursts: description and validation using synthetic data. Analytical Biochemistry 2008381 8-17. (https://doi.org/10.1016/j.ab.2008.07.001)

17 Zadik Z, Chalew SA \& Kowarski A. The definition of a spontaneous growth hormone $(\mathrm{GH})$ peak: studies in normally growing and GH-deficient children. Journal of Clinical Endocrinology and Metabolism 199274 801-805. (https://doi.org/10.1210/jcem.74.4.1548344)

18 Pincus S. Approximate entropy (ApEn) as a complexity measure. Chaos 19955 110-117. (https://doi.org/10.1063/1.166092)

19 Pincus SM, Mulligan T, Iranmanesh A, Gheorghiu S, Godschalk M $\&$ Veldhuis JD. Older males secrete luteinizing hormone and testosterone more irregularly, and jointly more asynchronously, than younger males. PNAS 199693 14100-14105. (https://doi. org/10.1073/pnas.93.24.14100)

20 Freeman JV, Cole TJ, Chinn S, Jones PR, White EM \& Preece MA. Cross sectional stature and weight reference curves for the UK, 1990. Archives of Disease in Childhood 199573 17-24. (https://doi. org/10.1136/adc.73.1.17)
21 Bercu BB, Shulman D, Root AW \& Spiliotis BE. Growth hormone (GH) provocative testing frequently does not reflect endogenous $\mathrm{GH}$ secretion. Journal of Clinical Endocrinology and Metabolism 198663 709-716. (https://doi.org/10.1210/jcem-63-3-709)

22 Koltowska-Haggstrom M, Hennessy S, Mattsson AF, Monson JP \& Kind P. Quality of life assessment of growth hormone deficiency in adults (QoL-AGHDA): comparison of normative reference data for the general population of England and Wales with results for adult hypopituitary patients with growth hormone deficiency. Hormone Research 200564 46-54. (https://doi.org/10.1159/000087444)

23 Cella M \& Chalder T. Measuring fatigue in clinical and community settings. Journal of Psychosomatic Research 201069 17-22. (https:// doi.org/10.1016/j.jpsychores.2009.10.007)

24 Binder G, Huller E, Blumenstock G \& Schweizer R. Auxology-based cut-off values for biochemical testing of GH secretion in childhood. Growth Hormone and IGF Research 201121 212-218. (https://doi. org/10.1016/j.ghir.2011.05.007)

25 Wamstad JB, Norwood KW, Rogol AD, Gurka MJ, Deboer MD, Blackman JA, Buck ML, Kuperminc MN, Darring JG \& Patrick PD. Neuropsychological recovery and quality-of-life in children and adolescents with growth hormone deficiency following TBI: a preliminary study. Brain Injury 201327 200-208. (https://doi.org/10. 3109/02699052.2012.672786)

26 Bushnik T, Englander J \& Katznelson L. Fatigue after TBI: association with neuroendocrine abnormalities. Brain Injury 200721 559-566. (https://doi.org/10.1080/02699050701426915)

27 Leal-Cerro A, Povedano J, Astorga R, Gonzalez M, Silva H, GarciaPesquera F, Casanueva FF \& Dieguez C. The growth hormone (GH)releasing hormone-GH-insulin-like growth factor-1 axis in patients with fibromyalgia syndrome. Journal of Clinical Endocrinology and Metabolism 199984 3378-3381. (https://doi.org/10.1210/jcem.84.9.5982)

Received 9 March 2019

Revised version received 14 July 2019

Accepted 18 July 2019 